\title{
AVALIAÇÃO DE DESEMPENHO ECONÔMICO-FINANCEIRO DE UMA EMPRESA EM RECUPERAÇÃO JUDICIAL: ESTUDO DE CASO OI S.A.
}

\section{EVALUATION OF ECONOMIC-FINANCIAL PERFORMANCE OF A COMPANY IN JUDICIAL RECOVERY: CASE STUDY OI S.A.}

\author{
E. R. A. SANTOS ${ }^{1}$, M. M. CORCETI ${ }^{1,}$ M. D. RAMOS ${ }^{1}$, T. LATARINI ${ }^{1}$, A.D. PELLICANI ${ }^{1, *}$ \\ ${ }^{1}$ Centro Universitário Hermínio Ometto (FHO-Uniararas), Núcleo de Engenharia, Araras, São Paulo, Brazil
}

${ }^{*}$ Corresponding author. Centro Universitário Hermínio Ometto, Núcleo de Engenharia, Araras, São Paulo, Brazil, Phone: +55 19 35431400; e-mail: alinepellicani@fho.edu.br (A. D. Pellicani

\begin{tabular}{|c|}
\hline A R T I C LE IN F O \\
\hline $\begin{array}{l}\text { Article history: } \\
\text { Received 2019-11-11 } \\
\text { Accepted 2020-01-03 } \\
\text { Available online 2020-02-15 }\end{array}$ \\
\hline $\begin{array}{l}\text { palavras -chave } \\
\text { Desempenho financeiro } \\
\text { Endividamento } \\
\text { Telecomunicações } \\
\text { Estrutura de Capital }\end{array}$ \\
\hline $\begin{array}{l}\text { keywords} \\
\text { Financial performance } \\
\text { Debt } \\
\text { Telecommunication } \\
\text { Capital Structure }\end{array}$ \\
\hline
\end{tabular}

\begin{abstract}
R E S U M O
O presente estudo fundamenta-se nos balanços e demonstrativos dos resultados da Oi S.A. entre os anos de 2002 e 2016 para analisar os fatores que a levaram a declarar recuperação judicial. Os indicadores financeiros sugerem que a fragilidade da Oi S.A. é proveniente da captação de dívida de curto prazo. Em meados de 2016 houve uma tentativa de reestruturação da dívida da empresa, mas o fato de a companhia demonstrar insustentabilidade também pode ter influenciado na captação de recursos. Soma-se a isso, as constantes quedas de rentabilidade, instabilidade de governança corporativa, constantes multas aplicadas à empresa e os processos judiciais enfrentados, também agravaram a saúde financeira da empresa.
\end{abstract}

\section{A B S T R A C T}

This study is based on the balance sheets and income statements of Oi S.A.'s in the period from 2002 to 2016 to analyze the factors that led in judicial recovery process. The indicators suggest that financial situation of Oi S.A. is highly influenced by short-term debt. In mid-2016, the company tried to restructure the company's debt, but as Oi S.A had no financial sustainability, it may have negatively influenced on fundraising. Thus, as constant income declines, corporate governance instability, constant fines imposed on the company and the lawsuits faced, the company's financial health collapsed. 


\section{INTRODUÇÃO}

No Brasil, país com dimensões continentais, a necessidade de integração de territórios e pessoas se faz necessária e fundamental para o desenvolvimento econômico, social e cultural. Nos últimos anos, o aumento do poder aquisitivo juntamente com as mudanças tecnológicas, fomentaram a ampliação e modernização das redes. Os recursos utilizados nas decisões de financiamento para investimentos provem de terceiros ou de autofinanciamento (capital próprio). Entender essa dinâmica do financiamento no desempenho de curto ou longo prazo de uma empresa determina a eficiência da decisão e atratividade para investidores. Os indicadores de atratividade, endividamento, e solvência mostram a saúde financeira da empresa, buscando analisar a capacidade de saldar obrigações e de possível inadimplência. (DA SILVA e colab., 2013).

Para análise de desempenho econômico, a Oi S.A., empresa de telecomunicações fundada em 2002, foi escolhida pela sua importância nacional sendo a principal provedora de telefonia fixa em todo território brasileiro, exceto o estado de São Paulo, com 12,9 milhões de assinaturas segundo dados do website corporativo. Essa escolha é também justificada pela alta relevância da empresa no setor, que nos últimos anos enfrenta constantes mudanças estruturais e de perfil dos usuários, com o aumento da tecnologia móvel. No Brasil, as ações coordenadas pelo governo para garantir uma estrutura sólida de telecomunicações para a economia, evidenciam a convergência com o setor privado para a formação deste mercado (MOCELIN e BARCELOS, 2012).

Telecomunicação é classificada como a transmissão, emissão e recepção por diferentes meios, de símbolos, caracteres, sinais, escritos, imagens e sons ou outro de qualquer natureza segundo Lei Geral de Telecomunicações art.60, $\S 1^{\circ}$. A necessidade de comunicação eficaz, oriunda da rápida globalização, demanda investimentos constantes das empresas de telecomunicações no Brasil e no mundo. O setor de telecomunicações em 2017 movimentou R\$ 233 bilhões, correspondente a 3,6 \% do PIB anual, segundo a TELEBRASIL (2018).

Várias empresas foram criadas a partir da privatização da Telebras em 1998. Dentre estas, as companhias Telemar Norte e Brasil Telecom, sendo a Brasil Telecom comprada pela Oi S.A. (antiga Telemar Norte) em 2008. Com a aquisição, o Grupo Oi era o quarto maior listado na Bovespa, possibilitando a oportunidade de efetuar compra de ativos no exterior (FEITOSA;SILVA e FIRMO, 2009). Em junho de 2016 a Oi S.A. entrou com pedido de recuperação judicial, deferido pelo Juízo da $7^{\text {a }}$ Vara Empresarial da Comarca da Capital do Estado do Rio de Janeiro. Tal pedido, considerado o maior da história brasileira até o momento, registrou cerca de $\mathrm{R} \$ 65$ bilhões em dívidas, e aproximadamente 55 mil credores envolvidos.

Assim, o presente estudo embasado nos índices de endividamento, rentabilidade e liquidez, busca entender quais fatores determinaram a insolvência da Oi S.A. Os dados utilizados estão disponíveis nos demonstrativos financeiros dos anos de 2002 a 2016 na página da CVM (Comissão de Valores Mobiliários). No estudo se destaca a importância em entender os fatores de riscos presentes nas decisões financeiras nos últimos anos da empresa em análise e a necessidade em indicar as razões para inadimplência, apesar do crescimento e evolução do setor em que a empresa se encontra.

\section{REVISÃO BIBLIOGRÁFICA}

O atual cenário do mercado demonstra certo nível de dependência das tecnologias da informação, com isso o setor de telecomunicações assume um papel de extrema relevância, que é garantir a troca de informações. A relevância do setor de telecomunicações está na necessidade de seu uso na infraestrutura em geral (transportes, redes elétricas, agricultura, educação, saúde, setores governamentais e de negócios). Com as inovações tecnológicas decorrentes dos últimos anos, criouse a necessidade de investimentos do setor em novos dispositivos, infraestrutura, modernizações, adaptações ou ampliação no atendimento da demanda. Um exemplo é a substituição do telefone fixo pelo móvel, fazendo com que seja imprescindível a ampliação e investimentos em suas redes de atendimento. A demanda por acesso à internet, e a popularização de bens tecnológicos como laptops, tablets e smartphones cria oportunidades de investimentos no setor e contribui para a acessibilidade tecnológica na sociedade.

A Oi S.A. insere-se nesse mercado como uma grande protagonista. A empresa iniciou suas atividades com a prestação de serviços em telefonia fixa e expandiu sua atuação para os serviços móveis, internet e TV, após diversas negociações até tornar-se um conglomerado de empresas que operam com o nome "Oi”. O Grupo Oi destacou-se por ser o maior prestador de serviço de telefonia fixa na América Latina e no Brasil, até 2016. O grupo presta serviço de telefonia com exclusividade, às unidades do exército localizadas na fronteira seca do Brasil e opera o sistema de telecomunicações da estação Comandante Ferraz, na Antártica. Destaca-se também a grande participação da Oi S.A. no que diz respeito à arrecadação tributária recolhida de 2013 a 2016 em torno de R \$34 bilhões à União e pela geração de empregos que até a data contabilizava cerca de 132 mil postos de trabalho no Brasil. Sua importância social é notada em iniciativas como o "Oi Futuro" que trata de projetos em educação, sustentabilidade, cultura e esporte, e na participação da administração do Plano Nacional de Banda Larga e Banda Larga nas Escolas. O Grupo Oi se responsabiliza pela apuração de votos nas eleições em cerca de 13 mil seções eleitorais, está presente em aproximadamente 5,5mil municípios do país, com número de clientes em torno de 65 milhões e disponibiliza seus serviços a diversas áreas remotas que outras operadoras não se propuseram a investir (PLANO DE RECUPERAÇÃO JUDICIAL DO GRUPO OI, 2017).

Em 2016 junto com as outras empresas do Grupo Oi, a Oi S.A. entrou com pedido de recuperação judicial no Brasil. A atual situação financeira da empresa decorre de diversos fatores, dos quais destaca-se a quantidade significativa de processos judiciais trabalhistas, fiscais e cíveis, as multas administrativas aplicadas pela ANATEL, o extenso processo de concessão para a entrada no mercado de telefonia móvel unida ao declínio do mercado de telefonia fixa. Adicionalmente, a obrigação da Oi S.A. em realizar grandes investimentos em regiões remotas, com baixa densidade demográfica e população com baixo poder aquisitivo, conforme contrato assinado em 1998 do Plano Geral de Metas de Universalização, também corroborou para o mau desempenho da empresa ao longo dos anos. 
As altas taxas de juros cobradas na captação de recursos para a Oi S.A. e as outras empresas do Grupo Oi, os custos com o serviço de telefones públicos (comumente chamados de "orelhões") instalados em todo o Brasil (exceto no estado de São Paulo) e finalmente a crise financeira que grande parte das empresas no Brasil enfrenta, também contribuíram para o insucesso em suas atividades.

Lançamentos de novos planos de comunicações, combos de produtos, redução de custos e despesas, melhoria na qualidade de serviço e consequente redução do custo de manutenção corretiva foram algumas medidas já adotadas e que trouxeram resultados para a empresa. A Oi S.A. se sobressai pela importância social, infraestrutura e tamanho que alcançou ao longo dos anos, e mesmo instável têm obtido bons resultados em medidas provisoriamente adotadas antes que o acordo de recuperação judicial fosse totalmente aceito pelas partes interessadas.

O Plano de Recuperação Judicial da Oi S.A. conta com muitos acordos com seus credores no que diz respeito a prazos, taxas de juros e início da liquidação de dívidas, aumento de capital para modernização da sua infraestrutura, implementação de um novo plano de negócios, reorganização societária, reestruturação na governança corporativa e a criação de um Conselho de Administração.

No caso da empresa em estudo, isso será muito necessário nos próximos anos, tendo em vista a captação de recursos externos para a empresa. É importante salientar que um dos grandes desafios para a Oi S.A. no seu Plano de Recuperação Judicial é a reestruturação de sua dívida. De acordo com a teoria do Trade off, as empresas buscam um ponto ótimo de endividamento considerando tanto o benefício fiscal como os custos de dificuldades financeiras (BASTOS E NAKAMURA, 2009).

Por se tratar de uma empresa brasileira de capital aberto, de acordo com Bastos e Nakamura(2009), a Teoria do Pecking Order é a que normalmente explica o comportamento das decisões de investimentos no Brasil, mas quando trata-se de investimentos em empresa de capital aberto é evidente a necessidade da simetria de informações, sendo primordial ter um vasto conhecimento sobre as empresas em que se está investindo e se relacionando.

Há diversas formas de se analisar a saúde financeira de empresas de capital aberto e para cada caso adota-se uma metodologia de análise. Para investigar o comportamento e desempenho financeiro da Oi S.A. ao longo dos anos, é necessário analisar os índices financeiros, que evidenciam a saúde financeira da empresa e suas perspectivas de mercado. $\mathrm{Na}$ análise dos demonstrativos é possível identificar, desde seus imobilizados, direitos e obrigações a curto e longo prazo e toda sua estrutura patrimonial. Segundo Assaf Neto (2002) a comparação dos dados entre si, e com outros de diferentes períodos proporciona uma perspectiva mais dinâmica e esclarecedora à posição estática das demonstrações contábeis. Tais demonstrativos têm grande importância, mostrando os seus resultados e as proporções da empresa, embasando a conclusão de se a empresa tem ou não um potencial econômico para permanecer no mercado (ASSAF NETO, 2007).

Os índices financeiros colaboram com o entendimento da saúde financeira, sendo estes liquidez, endividamento e rentabilidade. Tais índices apresentam fatores determinantes para análises de balanços (MATARAZZO, 1998).

Ainda de acordo Iudícibus (2009), o principal objetivo do balanço é comparar o que ocorreu com a saúde financeira da empresa no passado, para que possamos tomar decisões de ações para possíveis resultados futuros, sejam eles estratégicos ou decisórios. Em sequência é considerado que todas as decisões tomadas serão realizadas com base nesse conjunto de indicadores (BRUNI, 2014).

\section{METODOLOGIA}

O estudo baseou-se em dados de demonstrativos financeiros do período de 2002 a 2016 . Foi realizada a coleta de dados econômico-financeiros do Grupo Oi, cujo capital é negociado na B3 (Bolsa de Valores de São Paulo). As informações utilizadas estão disponibilizadas no website da B3 e no website da Comissão de Valores Mobiliários (CVM). Perlin, Kirch, Vancin (2018) disponibilizaram por meio do software estatístico R, pelo pacote "GetDFPData" estes dados da CVM desde o ano de 1997, facilitando seu uso pela comunidade acadêmica. Sendo assim, este estudo utilizou deste recurso gratuito para acessar as séries temporais necessárias para essa pesquisa.

Dentre os objetivos, buscou-se observar adversidades no comportamento financeiro da empresa. Para isso utilizou-se índices econômico-financeiro, como os de liquidez, endividamento e rentabilidade. Tais índices geram resultados que possibilitam o entendimento das contas da empresa em relação a sua estratégia de administração e ao mercado. Os dados utilizados nos cálculos foram deflacionados de acordo com IPCA (índice de preços ao consumidor amplo), a fim de considerar a dinâmica do valor ao longo do tempo e de torná-los diretamente comparáveis. Para Iudícibus (2009), na análise de balanços por cálculos de quocientes têm-se a vantagem de que, dividindo-se um valor pelo outro, os efeitos da inflação são depurados, isto aplicado apenas aos índices financeiros. Para análise do ativo imobilizado foi utilizada a variação percentual do ativo imobilizado (taxa de investimento).

O estudo de caráter investigativo utiliza-se dos valores calculados pelos índices para identificar se houve crescimento positivo ou negativo da empresa, como o aumento endividamento. Com estes cálculos, pode-se observar os riscos e oportunidades que a empresa dispõe em suas finanças. Os grupos dos índices utilizados nesse estudo são: liquidez, endividamento (e estrutura) e rentabilidade. O quadro 1 apresenta os indicadores de liquidez utilizados:

\begin{tabular}{|lc|}
\hline \multicolumn{1}{c|}{ Quadro 1 - Indicadores de Liquidez } \\
\hline \multicolumn{1}{|c|}{ Indicador } & Fórmula \\
\hline Liquidez corrente & $\frac{\text { Ativo Circulante }}{\text { Passivo circulante }}$ \\
\hline Liquidez seca & Ativo Circulante- Estoques - Despesas Antecipadas \\
\cline { 2 - 2 } & Passivo Circulante \\
\hline Liquidez imediata & $\frac{\text { Disponível }}{\text { Passivo Circulante }}$ \\
\hline
\end{tabular}

$\mathrm{Na}$ análise dos resultados de liquidez compreende-se: 
1) Quando o índice resulta em um valor maior que 1 entendese que a empresa possui folga financeira e assim, é capaz de cumprir com suas obrigações financeiras.

2) Quando resulta em 1, é identificado que a empresa tem recursos necessários (e equivalentes) disponíveis para saldar suas contas.

3) Por fim, quando o resultado é inferior a 1, entende-se que a empresa possui dificuldades financeiras de curto e longo prazo.

O grupo de indicadores de liquidez gera informações importantes condizentes à folga financeira da empresa. Conforme Assaf Neto e Lima (2014, p.240), os indicadores de liquidez informam a situação das finanças num período especifico da coleta de dados. Assim, pode-se considerar que tais resultados são alterados de acordo com as variações das políticas de administração financeira da empresa, sendo necessária uma apurada observação e gerenciamento dos períodos dos valores calculados nos índices.

$\mathrm{Na}$ liquidez corrente, consideram-se apenas itens de curto prazo, resultando na capacidade imediata que a empresa possui para cumprir com suas obrigações financeiras de curto prazo. Segundo Assaf Neto e Lima (2014, p. 240), esse índice mede a relação entre o ativo circulante e o passivo circulante, ou seja, a cada \$1,00 aplicado em haveres e direitos (disponível, valores a receber e estoques) quanto a empresa deve também a curto prazo (duplicatas a pagar, dividendos, impostos, etc).

$\mathrm{Na}$ liquidez seca, subtraem-se os estoques dos ativos circulantes objetivando eliminar uma fonte de incerteza, devido a significativa rotatividade dos estoques (IUDÍCIBUS, 2009). O resultado pode ser entendido como a parcela das dívidas que a empresa pode saldar em curto prazo utilizando ativos de maior liquidez, como o disponível e contas a receber, ou seja, "o percentual que pode ser resgatado mediante o uso de ativos circulantes de maior liquidez" (ASSAF NETO; LIMA, 2014, p. 240).

Na liquidez imediata, o cálculo resulta na porcentagem das dívidas de curto prazo que a empresa se dispõe em saldar imediatamente, com os valores disponíveis em caixa e equivalentes de caixa. Sendo assim, quanto maior for esse índice, maior o recurso disponível para possíveis problemas financeiros de prazos reduzidos.

Os indicadores de endividamento e estrutura são utilizados para analisar a relação entre capital próprio e capital de terceiros, indicando o nível de dependência de recursos da empresa a capitais de fontes externas, ou seja, identificam o nível de endividamento e o grau de independência financeira em relação a recursos externos. O quadro 1 apresenta os indicadores de endividamento utilizados no estudo.

O cálculo que relaciona o capital de terceiros e o ativo total, é obtido com a soma do passivo circulante com o passivo não circulante, e então dividido pelo ativo total. Conhecido como índice de dependência financeira, estima a porcentagem dos recursos totais (ativo total) que são financiados por terceiros.
É um índice de grande importância no qual, quanto maior o resultado, mais alta é a dependência financeira da empresa. Utilizou-se também os índices calculados a partir dos quocientes entre passivo não circulante e ativo total, e entre passivo circulante e ativo total, estes por sua vez detalham qual o nível dívida proveniente de curto ou longo prazo.

\begin{tabular}{|} 
Quadro 2 - Indicadores de endividamento \\
\begin{tabular}{|cc|}
\hline Indicador & Fórmula \\
\hline Dívida total & Passivo não circulante + Passivo Circulante \\
\cline { 2 - 2 } & Ativo Total \\
\hline $\begin{array}{c}\text { Dívida de Curto } \\
\text { Prazo }\end{array}$ & $\frac{\text { Passivo Circulante }}{\text { Ativo Total }}$ \\
\hline $\begin{array}{c}\text { Dívida de Longo } \\
\text { Prazo }\end{array}$ & $\frac{\text { Passivo não circulante }}{\text { Ativo Total }}$ \\
\hline
\end{tabular}
\end{tabular}

No grupo de indicadores de rentabilidade utilizou-se os cálculos que envolvem as margens de vendas. Esses indicadores estão apresentados no quadro 3. Os resultados gerados são base de análise das atividades de vendas da empresa e seu desempenho em gerar lucros por meio da receita. O cálculo da margem líquida resulta no valor efetivo do lucro da empresa, ou seja, qual a parcela da receita é lucro real. É obtido a partir da divisão do lucro líquido pela receita líquida de vendas após as deduções de impostos. Esse indicador também apresenta a proporção de despesa e lucro da receita líquida, é geralmente analisado em porcentagem. O cálculo da margem operacional resulta no valor das despesas operacionais (recursos aplicados na produção dos produtos e ou prestação de serviço) que é deduzido das receitas de vendas. É utilizado para checar se a empresa é lucrativa e qual o valor do lucro. Esse indicador mostra quanto a empresa obtém do retorno de vendas.

O ROA (sigla em inglês return on assets, entendido como retorno sobre ativo) é "a taxa de retorno gerado pelas aplicações em seus ativos. Apresenta o retorno gerado por cada \$ 1,00 investido pela empresa em seus ativos" (ASSAF NETO; LIMA, 2014, p. 245). Já o ROE (sigla em inglês return on equity, entendido como retorno sobre o patrimônio líquido) é o indicador que mede o retorno dos investimentos feitos pelos proprietários da empresa.

\section{Quadro 3 - Indicadores de rentabilidade}

\begin{tabular}{|cc|}
\hline Margem líquida & \multicolumn{1}{c|}{ Fórmula } \\
\hline Margem Operacional & $\frac{\text { Vucro líquido }}{\text { Vendas }}$ \\
\hline ROA & $\frac{\text { Lucro Operacional }}{\text { Vendas }}$ \\
\hline ROE & $\frac{\text { Lucro líquido }}{\text { Ativo total }}$ \\
\hline & $\frac{\text { Lucro líquido }}{\text { Patrimonio líquido }}$ \\
\hline
\end{tabular}




\section{RESULTADOS}

Com base nas informações coletadas, construiu-se a Tabela 1, que apresenta as variações de Ativo total, de passivo não circulante e passivo circulante em relação ao ativo total e a taxa de investimento (variação percentual do ativo imobilizado), entre 2002 e 2016.

$\mathrm{O}$ ativo total é uma medida utilizada para examinar o tamanho da empresa. Nos dados apresentados na tabela 1, percebe-se pequenas variações até o ano de 2011. Em 2012, quando se comparado ao ano de 2011, nota-se que a empresa dobra de tamanho (o ativo total de 2012 é 2,04 vezes maior do que o de 2011). A partir de 2012, observa-se aumentos consideráveis no ativo total, que só decresce em 2016. O aumento de 2012 ocorre devido a reorganização societária terminada em março de 2012, das empresas Tele Norte Leste Participações S.A.("TNL"), Telemar Norte Leste S.A. ("TMAR"), Coari Participações S.A. ("Coari”) e Brasil Telecom S.A.(BRT). A reorganização se compreendeu na incorporação da TMAR pela Coari, também da Coari e da TNL pela BRT, sendo essa a única listada na bolsa de valores, concentrando todas as participações das companhias, denominando-se Oi S.A. Em consequência, foram emitidas 395.585 .453 novas ações ordinárias e 798.480.405 novas ações preferenciais da Oi S.A.

Na Tabela 1, na coluna de dívida por ativo total há dois momentos, no primeiro, até o ano de 2011 a empresa tem em média uma estrutura de capital em que $60 \%$ do ativo total é dívida. No segundo momento, a partir de 2012, a estrutura de capital é modificada, aumentando-se o nível de capital de terceiros para a média de $83 \%$. A emissão de debêntures ocorridas com a reorganização societária, aumentam a sua dívida, utilizadas para financiar seus investimentos. No passivo não circulante, a companhia mantém um nível de endividamento de longo prazo em relação ao ativo de 35\% até 2011, aumentando para 59\% em 2012, oscilando nos anos subsequentes, quando em 2016 passa a representar apenas $11 \%$ do ativo. No passivo circulante não há alterações significativas até o ano de 2014 , quando este representa $41 \%$ do ativo total, volta a $26 \%$ em 2015, mas aumenta consideravelmente em 2016, correspondendo a $74 \%$ do ativo total.

O comportamento do passivo circulante e não circulante em 2016 evidencia os custos de agência, quando na ocasião a administração não conseguiu assumir dívidas de longo prazo em virtude de já existirem em seu histórico indícios de insustentabilidade do negócio, devendo assumir dívidas mais curtas e menos onerosas. Na variação do ativo imobilizado (taxa de investimento), percebe-se que entre os anos de 2003 e 2008 a empresa desinvestiu, apresentando queda na variação do imobilizado. Isso sugere que a empresa pode ter vendido ativos de longo prazo para gerar disponível. A variação do imobilizado é positiva somente em 2009 e no período entre 2011 e 2013.

As mudanças identificadas no aumento do investimento em ativo imobilizado em 2012, podem ter relação com o aumento do passivo não circulante ocorrido no mesmo ano, sendo este utilizado para financiar o investimento ocorrido. No caso dos anos seguintes a 2013, o nível de investimento diminui, podendo ter relação com o aumento no passivo circulante e a maior necessidade de aumento de caixa para quitar dívidas de curto prazo. O aumento de caixa pode ser identificado nos liquidez imediata, presente no gráfico 1 .
Em relação à política de investimentos, a Oi S.A. após sua reestruturação societária, em abril de 2012 divulgada por meio de seu Relatório de sustentabilidade anual OI S.A. (2012), registrou um plano de investimentos estipulado em $\mathrm{R} \$ 24$ bilhões no período de 2012-2015 (considerando os riscos do mercado), tendo como foco ações de melhorias em sua estrutura no mercado. Em 2013, "a diretoria do BNDES aprovou financiamento de R \$ 5,4 bilhões para o Grupo Oi, destinados ao plano de investimentos relativo ao triênio 2012-2014" (BNDES, 2013), visando a aquisição de equipamentos e ampliação de serviços 3G e de banda larga, implantação de 4G em grandes centros do país, assim como a aquisição de equipamentos de fibra ótica. Tais investimentos foram realizados visando obter maior marketshare da companhia no mercado competitivo atual.

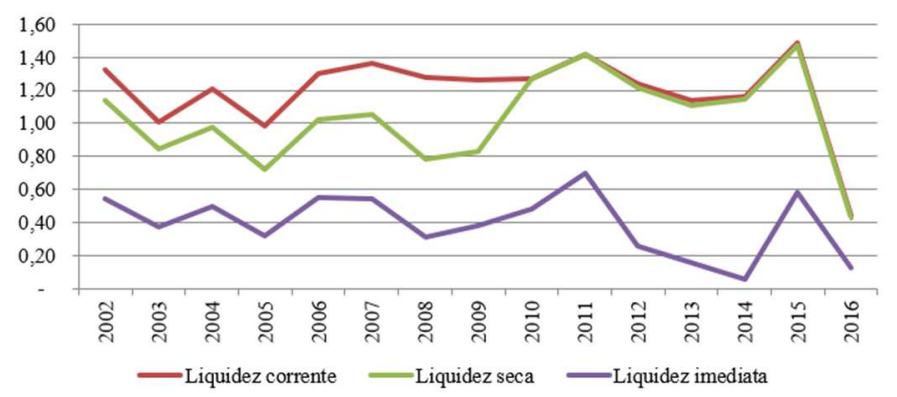

\section{Gráfico 1: Índices de liquidez}

Os índices de liquidez demonstram que a partir de 2012, houve diminuição, o que é justificado pelo aumento das dívidas de curto prazo a partir deste ano. Sendo estes índices calculados a partir do ativo circulante, demonstram a dificuldade da empresa em saldar seus compromissos de curto prazo. $\mathrm{O}$ fato de a liquidez seca e liquidez corrente serem próximas ou iguais a partir de 2010, indica menor participação do estoque e despesas antecipadas na conta ativo circulante nos anos subsequentes.

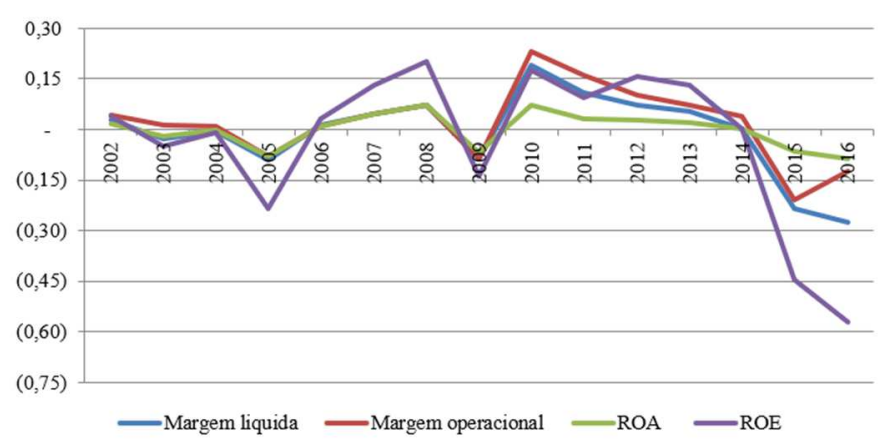

\section{Gráfico 2: Índices de Rentabilidade}

$\mathrm{Na}$ análise dos índices de rentabilidade, apresentados no gráfico 2, observa-se quedas contínuas a partir de 2012. A Oi S.A. organiza seus serviços por áreas, sendo estas, mobilidade pessoal, corporativa e residencial, com isso é possível identificar com precisão as evoluções em cada um dos setores. De $2012 \mathrm{em}$ diante, as reduções nas margens podem ser justificadas pela alta concorrência no mercado, provocado pelas perdas de clientes nos setores. De 2012 a meados de 2015 as quedas foram compensadas, podendo ser compreendida pela variação equilibrada dos produtos comercializados pela Oi. S.A., como quedas no número de telefonia fixa, mas aumento no número de telefonia e banda larga móvel. 
Tabela 1 - Ativo total, endividamento e investimento em imobilizado da Oi S.A ao longo dos anos 2002-2016

\begin{tabular}{llcccc}
$\mathbf{A n o}$ & Ativo total & Dívida /Ativo Total & $\begin{array}{c}\text { Passivo não } \\
\text { Circulante/Ativo }\end{array}$ & $\begin{array}{c}\text { Passivo } \\
\text { Circulante/Ativo }\end{array}$ & $\begin{array}{c}\text { Taxa de } \\
\text { Investimento }\end{array}$ \\
\hline $\mathbf{2 0 0 2}$ & $4,05 \mathrm{E}+07$ & 0,55 & 0,38 & 0,17 & 0,00 \\
\hline $\mathbf{2 0 0 3}$ & $3,59 \mathrm{E}+07$ & 0,56 & 0,31 & 0,26 & $-0,20$ \\
\hline $\mathbf{2 0 0 4}$ & $3,73 \mathrm{E}+07$ & 0,62 & 0,35 & 0,28 & $-0,16$ \\
\hline $\mathbf{2 0 0 5}$ & $3,33 \mathrm{E}+07$ & 0,67 & 0,34 & 0,33 & $-0,15$ \\
\hline $\mathbf{2 0 0 6}$ & $3,01 \mathrm{E}+07$ & 0,65 & 0,37 & 0,29 & $-0,19$ \\
\hline $\mathbf{2 0 0 7}$ & $2,84 \mathrm{E}+07$ & 0,64 & 0,36 & 0,28 & $-0,16$ \\
\hline $\mathbf{2 0 0 8}$ & $3,09 \mathrm{E}+07$ & 0,65 & 0,38 & 0,27 & $-0,01$ \\
\hline $\mathbf{2 0 0 9}$ & $3,76 \mathrm{E}+07$ & 0,51 & 0,31 & 0,20 & 0,12 \\
\hline $\mathbf{2 0 1 0}$ & $4,25 \mathrm{E}+07$ & 0,58 & 0,33 & 0,25 & $-0,27$ \\
\hline $\mathbf{2 0 1 1}$ & $4,73 \mathrm{E}+07$ & 0,67 & 0,39 & 0,27 & 0,03 \\
\hline $\mathbf{2 0 1 2}$ & $9,69 \mathrm{E}+07$ & 0,84 & 0,59 & 0,25 & 2,75 \\
\hline $\mathbf{2 0 1 3}$ & $9,29 \mathrm{E}+07$ & 0,84 & 0,61 & 0,22 & 0,01 \\
\hline $\mathbf{2 0 1 4}$ & $1,29 \mathrm{E}+08$ & 0,81 & 0,40 & 0,41 & $-0,02$ \\
\hline $\mathbf{2 0 1 5}$ & $1,14 \mathrm{E}+08$ & 0,85 & 0,59 & 0,26 & $-0,04$ \\
\hline $\mathbf{2 0 1 6}$ & $8,73 \mathrm{E}+07$ & 0,85 & 0,11 & 0,74 & $-0,09$ \\
\hline Média & $5,89 \mathrm{E}+07$ & 0,69 & 0,39 & 0,30 & 0,11 \\
\hline
\end{tabular}

\section{CONSIDERAÇÕES FINAIS}

O estudo evidencia a necessidade de adaptabilidade de empresas como a Oi S.A., frente às mudanças tecnológicas, que no caso do setor de telecomunicações afetam diretamente o perfil e a necessidade do consumidor. Sendo assim, é fundamental que os investimentos acompanhem a essa dinâmica de mercado, pois a continuidade das atividades baseia-se na qualidade e assertividade das decisões.

A crise presente no mercado brasileiro influência na disponibilidade de capital, que se torna escasso e mais oneroso. Conforme relatado no Plano de Recuperação Judicial do Grupo Oi (2017), uma das causas para a crise da empresa foram às altas taxas de juros praticadas nacionalmente para captação de recursos. A captação de recursos se justifica pelo plano estratégico elaborado pela companhia, visando maiores investimentos em novas tecnologias.

A instabilidade agravada pela sucessão constante de presidentes, falta de confiança entre os administradores, potencializa a decadência de resultados da companhia. As multas aplicadas pela ANATEL contribuem diretamente ao aumento das dívidas da companhia ao longo dos anos. A mudança no nível de endividamento da OI S.A. ocorrida em 2012, aconteceu como uma medida estratégica de captação de recursos, focando em melhorias nos seus serviços e produtos. A dificuldade enfrentada pela companhia em captar recursos de longo prazo, a partir de 2016, é explicada pela oscilação de sua rentabilidade e crescimento de dívidas, que dentre outros fatores afetam a imagem da empresa no mercado.

No período estudado, a empresa, apesar da instabilidade do ano de 2012 e subsequentes, se mostrou rentável nos anos anteriores, isso sinaliza perspectivas positivas de recuperação, se houver um eficiente gerenciamento de sua dívida. Melhorar a sua imagem perante os investidores aparenta ser uma medida viável para a captação de recursos de longo prazo que possibilitem investimentos futuros. A difusão de práticas de governança corporativa no Grupo Oi, traz ferramentas que otimizam a estrutura e o custo de capital, permitindo a consolidação da empresa no mercado competitivo.

\section{R E FER Ê N C I A S}

ASSAF NETO, Alexandre. Estrutura e análise de balanços: um enfoque econômico financeiro. 7.ed. São Paulo: Atlas, 2002.

BASTOS, Douglas Dias e NAKAMURA, Wilson Toshiro. Determinantes da estrutura de capital das companhias abertas no Brasil, México e Chile no período 2001-2006. Revista Contabilidade \& Finanças, v. 20, n. 50, p. 75-94, 2009.

BNDES. BNDES aprova financiamento de $R \$ 5,4$ bilhões para a Oi. 2013. Disponível em: $<$ https://www.bndes.g ov.br/wps/portal/site/home/imprensa/noticias/conteudo/ 20130108_oi>. Acesso em 23 de setembro de 2018.

BRUNI, Adriano Leal. A análise contábil e financeira. 3.ed. São Paulo: Atlas, 2014, 329 p.

DA SILVA, Polyandra Zampiere Pessoa e colab. A Teoria da Sinalização e a Recuperação Judicial: Um Estudo nas Empresas de Capital Aberto Listadas na BM\&Bovespa. XV Congresso USP Controladoria e Contabilidade, v. 16, p. 1-16, 2013.

FEITOSA, Maria José da Silva; DA SILVA, Minelle Enéas; FIRMO, Luciene Alencar. Fusões e aquisições empresariais no contexto brasileiro: o caso da OI e 
BRASIL TELECOM. Revista Razão Contábil \& Finanças, v. 2, n. 1, 2012.

IUDÍCIBUS, Sérgio de.Análise de balanços.10.ed.São Paulo: Atlas, 2009.254p.

MATARAZZO, D. C. Análise financeira de balanços: abordagem básica e gerencial. 6. ed. São Paulo: Atlas, 2010.gerencial. 6. ed. São Paulo: Atlas, 2010.

MOCELIN, Daniel Gustavo e BARCELOS, Régis Leonardo Gusmão. Tecnologia, competitividade e regulação: a estruturação do mercado das telecomunicações no Brasil TT .Caderno CRH, v. 25, n. 66, p. 409-432, 2012.

NETO, Alexandre Assaf; LIMA, Fabiano Guasti. Curso de administração finaneira. 3. ed. São Paulo: Atlas, 2014. $880 \mathrm{p}$.

PAES, Antonio Tavares. A recuperação judicial da Oi e sua influência nos próximos processos. Disponível em:< https://politica.estadao.com.br/blogs/fausto-macedo/arecuperacao-judicial-da-oi-e-sua-influencia-nosproximos-processos/> Acesso em 08 de setembro de 2018.

Plano de Recuperação Judicial Consolidado do Grupo Oi. Disponível em: $<$ http://www.recuperacaojudi cialoi.com.br/wp-content/uploads/2017/12/Anexo-38PRJ-modificado_Parte1-Assinado.pdf > Acesso em 08 de setembro de 2018 .

Relatório de sustentabilidade anual OI S.A. [S.1.: s.n.], 2012. Disponível em: <http://ri.oi.com.br/downloa d_arquivos.asp?id_arquivo=528CC589-84A9-45FD9367-28164A1B67F5>. Acesso em 15 de setembro de 2018.

SALOMÃO, Karin. Os planos da Oi para se reerguer da maior recuperação judicial do Brasil. Disponível em:<<https://exame.abril.com.br/negocios/os-planosda-oi-para-se-reerguer-da-recuperacao-judicial-dahistoria/ >> Acesso em 08 de setembro de 2018.

TELEBRASIL, Associação Brasileira de Telecomunicações. Tabela Referência de Indicadores Para Análise. 2018.

TELEBRASIL. O Setor de Telecomunicações no Brasil - Uma Visão Estruturada. p. 47, 2014. Disponível em: $<$ http://www.telebrasil.org.br/panorama-do-setor/osetor-de-telecomunicacoes $>$. Acesso em 05 de setembro de 2018. 